\title{
Metode Dan Tantangan Penginjilan Di Dalam Pluralisme Agama di Indonesia
}

\author{
Septerianus Waruwu ${ }^{1 *}$, Abehud Bawadji ${ }^{2}$, Surya Kencana Meliala ${ }^{3}$, Susilo \\ Susanto $^{4}$, Hendrik Bernadus Tetelepta ${ }^{5}$ \\ 1,2, ${ }^{3}$ Mahasiswa Pasca Sarjana Prodi Teologi, STT Real Batam \\ ${ }^{4}$ Prodi Teologi, STT Real Batam \\ ${ }^{5}$ Prodi Doktoral Teologi, STT Real Batam \\ septewaruwu@gmail.com
}

\begin{abstract}
In Indonesia, to knit the diversity of the state not only on culture and language but also on beliefs. The plurality of religiosity has the potential to make strength as well as a threat to state stability. This is certainly a challenge in evangelism. Therefore, there needs to be an adequate understanding for believers to apply the understanding of their personal beliefs in the midst of religious pluralism in Indonesia. This study uses a peaceful evangelistic method by maintaining the integrity of the state in religious pluralism in Indonesia. This study will also provide information about the challenges and how to address them by finding the right method of evangelism in a pluralistic Indonesia.
\end{abstract}

Keywords: Evangelism Method, Challenge, Postmodern.

\begin{abstract}
Abstrak
Di Indonesia untuk merajut kebinekaan bernegara bukan hanya pada budaya dan bahasa tetapi juga pada kepercayaan. Kemajemukan religiositas berpotensi menjadikan kekuatan sekaligus dapat menjadi ancaman stabilitas bernegara. Hal ini tentunya menjadi tantangan dalam penginjilan. Oleh sebab itu, perlu ada pemahaman yang memadai bagi orang percaya untuk mengaplikasikan pemahaman kepercayaan pribadinya di tengah pluralisme agama di Indonesia. Penelitian ini menggunakan metode penginjilan yang bernuansa damai dengan menjaga keutuhan bernegara di dalam pluralisme Agama di Indonesia. Dalam kajian ini juga akan memberikan informasi mengenai tantangan dan bagaimana menyingkapi hal tersebut dengan menemukan metode yang tepat dalam penginjilan di Indonesia yang majemuk.
\end{abstract}

Kata kunci: Metote Penginjilan, Tantangan, Postmodern. 


\section{PENDAHULUAN}

Dewasa ini dikenal dengan istilahPostmodern. Apa itu postmodern? Secara sederhana dianggap kelanjutan dari moderenism. Apapun pendapatnya post-modern berkaitan erat dengan kemajuan didalam bidang-bidang seperti pada situasi dan tata sosial sosial produk teknologi informasi, globalisasi, fragmentasi gaya hidup, konsumerisme yang berlebihan, deregulasi pasar uang dan sarana publik, usangnya negara dan bangsa serta penggalian kembali inspirasi-inspirasi tradisi dikenal sebagai postmodernitas. ${ }^{1}$ Postmodernisme dibedakan dengan postmodernitas, jika postmodernisme lebih menunjuk pada konsep berpikir. ${ }^{2}$ Maka tentu dalam membahas hal-hal yang menyangkut Pluralisme berkaitan erat dengan Postmodernisme. Karena adanya hubnungan yang erat maka perlu kita juga memahami mengenai Pluralisme.

Oleh sebab itu, untuk memahami lebih jauh perlu dipahami bahwa puluralisme yang dimaksud di sini berkaitan dengan agama-agama dalam konteks Ke-Indonesiaan. Pluralisme agama bukanlah perbedaan antara satu dengan yang lain tetapi mengarah kepada bagaimana keyakinan itu dapat diterima di dalam masyarakat yang majemuk. Dr. Irwan F Widjaja menjelaskan bahwa Dalam perubahan antrapologi agama ini jadi agama tidak hanya dilihat pada tataran mitis ontolisnya, tetapi juga dalam tataran fungsionalnya, yakni bagaimana agama dan penganutnya memberi dampak bagi bumi yang di diami yang sangat plural dalam budaya dan keyakinan. ${ }^{3}$

Dengan adanya kondisi zaman yang terus berubah maka gereja memiliki tantangan baru untuk bermisi di Indonesia dalam era PosModernisme dengan corak pluralisme. Maka dengan demikian perlu ada metode penginjilan untuk tantangan tersebut. Oleh sebab itu Penulis ingin mengkaji mengenai Metode Dan Tantangan Penginjilan Di Dalam Pluralisme Agama di Indonesia.

\section{METODE}

Metode penelitian yang dipakai adalah metode kualitatif deskriptif dimana literatur dan journal menjadi objek utama dalam mendapatkan informasi sebagai data deskripsi dalam penelitian ini. Metode ini digunakan untuk menganilisa dan menemukan metode penginjilan di situasi pluralisme di Indonesia. Dimungkinkan penelitian ini untuk menolong gereja Tuhan agar

\footnotetext{
${ }^{1}$ Angga Permana Putra, "Pengertian Post Modernisme," Postmodernis.Blogspot.Com, last modified 2012, https://postmodernis.blogspot.com/2012/01/pengertian-post-modernisme.html.

${ }^{2}$ Ibid.

${ }^{3}$ Fransiskus Irwan Widjaja and Noh Ibrahim Boiliu, Misi Dan Pluralitas Keyakinan Di Indonesia (Yogyakarta: Andi Offset, 2019). 89
} 
dapat mengekpresikan amat agung Yesus Kristus tanpa konflik ditengah kemajemukan beragama di Indonesia.

\section{HASIL DAN PEMBAHASAN}

Indonesia termasuk negara yang memiliki beragam kepercayaan dan Agama. Indonesia memiliki agama yang diakui adalah Islam Kristen Protestan, Khatolik dan Budha, Hindu, kong fu Chu belum terhitung berbagai aliran yang lain yang juga tumbuh subur di Indonesia. Untuk menyingkapi hal ini tentu menjadi tantangan tersendiri bagi penginjilan di nusantara. Gereja mengemban tugas misi yaitu menjadikan semua bangsa murid Tuhan dan Baptiskan mereka yang percaya, serta mengajar mereka melakukan Firman Allah. Mat 28:19-20.

Seperti yang telah disinggung di atas bahwa pluralisme bukan menitik beratkan pada Ajaran dan pemahaman dari setiap kepercayaan tetapi yang dimaksud dalam pluralisme itu sendiri berkaitan dengan bagaimana sebuah ajaran dapat dikembangakan untuk dapat diterima sebagai bagian dari sumbangsi yang beraplikasi memberi dampak bagi bumi yang di huni. Jadi yang dimaksudkan bukan bagaimana seseorang mempercayai apa yang diyakininya tetapi bagaimana seseorang tersebut mempraktekan sesuatu ajaran yang dapat menjadi solusi untuk masa depan masyarakat Post-modern itu sendiri.

Akibat yang ditimbulkan adalah bahwa semua kepercayaan itu baik dengan wordlview bahwa semua agama itu baik selama menjawab dan memberi sumbangsi bagi kemanusiaan itu sendiri. Dengan demikian setiap agama akan tergerus pada keyakinan masing-masing dan dapat kehilangan karakteristik karena konsep pluralisme. Hal yang lain yang tidak kalah menarik adalah etika Kristen bisa menjadi etika teleologis yang hanya mengarah kepada tujuan dan bukan proses untuk mencapai tujuan. Sehingga menghalalkan segala cara dengan modus, "yang penting untuk kebaikan." walaupun akan bertabrakan dengan etika dari kepercayaan itu sendiri. Steven Tong mengatakan bahwa Kekristenan selalu berayun di antara dua ektrim. Yang satu menjurus ke arah rasional yaitu berpusat kepada kebudayaan dunia dan manusia. dan etrim berikutnya adalah berpuas kepada gereja yang menitikberatkan pada liturgie, berbalik kepada pengobralan emosi, meninggalkan pengajaran Alkitab yang ketat, dikatakan ini seperti racun bagi gereja. ${ }^{4}$ Gereja yang kehilangan Etika Kristen yang berdasarkan alkitab dapat 1988). 1

${ }^{4}$ Stephen Tong, Teologi Penginjilan (Jakarta: Lembaga Reformed Injili Indonesis, 
menjurus kepada etrim dimana ajaran alkitab tidak perlu menjadi patokan. Sehingga terjerumus kepada budaya dunia yang hedonisme dan duniawi.

Gereja juga perlu berhati-hati dengan istilah toleransi sehingga gereja tidak terjebak secara universalisme. Hanya karena istilah toleransi maka gereja terjebak kepada berkompromi dengan motivasi hanya karena keinginan mencapai satu tujuan yang sama. Gereja harus benar-benar dapat mengambil ruang untuk menyatakan kabar baik ditengah konsep pluralisme. Dalam konteks keIndonesiaan dalam buku yang berjudul Kontek berteologia di Indonesisa menekankan bagaimana beretika baik bagi semua agama bukan hanya pada etika kristen itu sendiri. ${ }^{5}$ Bagaimana Kriten hadir sebagai agen perubahan di dalam freming negara Pancasialisme.

Dalam pelayanan penginjilan kita tidak bisa lepas juga dari memahami idiologi pancasila itu sendiri. Tentu alasan yang sangat mendasar bahwa misi dan penginjilan yang dilakukan berada di negara Indonesia yang beridiologi Pancasila. Seperti yang diungkapkan dalam buku yang berjudul," Tantangan Gereja Di Indonesia" disana dikatakan bahwa," Allah menetapkan gereja sebagai sebuah lembaga untuk menjalankan tugasnya menjalankan pembangunan nasionalsebagai pengamalan Pancasila menuju tinggal landas, sebagai garam dan terang dan berkat bagi semua orang. ${ }^{6}$

Dalam menyatakan iman dari masing-masing kepercayaan, tentu ada perbedaan-perbedaan, bahkan ada perbedaan yang bergitu tajam bahkan bertentang antara ajaran yang satu dengan ajaran yang lain dalam lintas agama. Sehingga kemungkinan yang akan muncul dalam pewartaan injil adalah konflik antara Kristen itu sendiri dengan non kristen. Hal inilah yang harus kita hindari dalam aplikasi sehari-hari sebagai pelaksana dari amanat agung Yesus Kristus. Maka tentu dalam konteks ini perlu membangun jembatan yang disebut toleransi.

Oleh sebab itu, perlunya metode penginjilan mutahir dalam era postmodernisme. Dengan kata lain injil disampaikan dengan motivasi yang tulus tetapi dengan cara yang cerdik. Maka yang perlu ditemukan adalah metode apa yang harus dipakai dalam era-postmodrnisme ini.

${ }^{5}$ Johannes B Banawiratma, Konteks Berteologi Di Indonesia (Jakarta: BPK Gunung Mulia, 1988). 24-26

${ }^{6}$ Caleb Tong, Menuju Tahun 2000-Tantangan Gereja Di Indonesia: Sebuah Bunga Rampai Dalam Rangka Peringatan 25 Tahun Kependetaan Caleb Tong (Bandung: Pusat Literatur Euangelion, 1990). 13 


\section{Agama, Budaya Dan Tradisi}

Tiga hal yang perlu diwaspadai bagi semua pemberita injil yaitu Agama, Budaya dan Tradisi. Tiga hal ini khususnya di bumi Nusantara Indonesia memegang peranan penting. Yang dimmaksudkan adalah baik Agama, Budaya dan Tradisi adalah hal-hal yang saling mempengaruhi satu dengan yang lain. Walaupun Indonesia bukan negara agama tetapi Indonesia adalah negara yang beragama. Negara beragama tidak lepas dari suku budaya yang sangat berbeda satu dengan yang lain. Sehingga ada pepatah lama yaitu dimana bumi dipijak disitu langit dijunjung. Di dalam bermasyarakat ada budaya dan adat istiadat yang perlu dilestarikan bagi setiap daerah tertentu dengan sebutan kearifan lokal. Sehingga ada hukum-hukum adat yang mendominasi daerah-daerah tertentu disuatu tempat dimana suku-suku tersebut menetap. Kearifan lokal berhubungan secara spesifik dengan budaya tertentu dan mencerminkan cara hidup suatu masyarakat tertentu. Oleh sebab itu dalam menjalankan misi kristen perlu diperhatikan ketiga hal ini. Dengan menabrak semua unsur ini maka tentu akan muncul masalah ektern yang merugikan injil itu sendiri.

\section{Pengertian Penginjilan}

Penginjilan adalah cara yang digunakan atau sebuah metode untuk memenangkan jiwa. Jiwa-jiwa yang dimaksudkan disini adalah orang-orang yang terhilang yang belum menerima Yesus sebagai Tuhan dan Jusruslamat. Mereka harus menerima kabar baik yang disampaikan oleh seorang penginjil. Dengan demikian maka penting seorang utusan injil utnuk melakukan tugas penginjilan ini. Dalam kaitan dengan penginjilan H,L Senduk dalam bukunya yang berjudul "Penginjil yang Sukses" disana dikatakan: "Sebelum pekerjaan memenangkan jiwa itu menjadi suatu bahagian yang penting dalam hidup kita,maka kita tak dapat memimpin banyak orang dari kegelapan kepada terang yang kekal."7 Disini kita dapat menemukan bahwa Senduk ingin memberikan penekanan betapa pentingnya seorang Penginjil untuk meneyelesaikan pekerjaa Allah yang menjadi amanat Agung Yesus Kristus. Yakob Tomatala memandang bahwa penginjilan berakaitan erat Misi dimana hal ini merupakan isi hati Allah. ${ }^{8}$ Misi yang dalam pengertian dalam bahasa latin missio sepadan dengan kata Yunani apostello memiliki pwngertian mengirim dengan otoritas. ${ }^{9}$ Dari beberapa penjelasan diatas kita dapat

\footnotetext{
${ }^{7}$ H L Senduk, Penginjil Yang Sukses (Jakarta: Yayasan Bethel, 2008). 1

${ }^{8}$ Yakob Tomatala, Teologi Misi (Jakarta: Leadershio Foundation, 2003). 15

${ }^{9}$ Ibid. 16
} 
memberi arti yang lebih jauh bahwa misi dan penginjilan yang berkaitan erat tidak bisa diabaikan dalam pertumbuhan gereja di muka bumi ini.

\section{Penjilan Melalui Dialog Antara Umat Beragama dalam diskusi Apolegetika}

Penginjilan dengan menggunakan metode dialong antar umat beragama yang disertai dengan apologetika, disana masing-masing para peserta akan menyampaikan argumentasi-argumentasi yang sesuai dengan iman dan kepercayaa yang dianut. Metode ini tidak akan melukai perasaan agama-agama lain dan dilakukan dengan penuh kedasaran setiap peserta. Keberadaan manusia di antara keyakinan agama yang beragam memunculkan pertanyaan apakah hanya satu agama yang memiliki kebenaran final sementara agama- agama selebihnya tidak memiliki ketersingungan. Di Indonesia dewasa ini semakin disadari bahwa sesungguhnya masyarakat Indonesia merupakan masyarakat majemuk yang terdiri atas berbagai suku bangsa, bahasa, budaya, agama, dan lain-lain. Pluralitas yang kita alami sebagai kenyataan sering menjadi pemicu konflik dan ketegangan dalam hidup bermasyarakat dan hidup bersama.

\section{Dialog Sebagai Wujud kesaksian Gereja}

Dokumen Gereja seperti Ad Gentes dan Redemptoris Missio tidak memandang dialog sebagai sarana misi, melainkan menggaris-bawahi bahwa hidup bersama dalam kerjasama dan dialog dapat menjadi wujud kesaksian sebagai orang Kristen. Dialog tidak dipandang sebagai strategi kristenisasi, tetapi sebagai wujud konkret meneladan hidup Yesus Kristus Lewat dialog, Gereja ingin agar Kristus makin dicintai dan mengajak manusia mencintai sesama. Dalam kesaksiannya lewat dialog Gereja membantu umat manusia untuk bertobat dengan mengusahakan keadilan dan perdamaian.

\section{Dialog Sebagai Misi Penginjilan Kristiani}

Penginjilan bertujuan mempertobatkan dalam arti penerimaan bebas kabar baik Allah dan menjadi anggota Gereja. Dialog sebaliknya, mengandaikan pertobatan dalam arti kembali kepada hati Allah dalam kasih dan ketaatan pada kehendak-Nya. Dengan demikian, dialog tidak bertentangan dengan perutusan Gereja bila dipahami sebagai sarana dan metode untuk saling memperkaya dan saling mengenal. Irwan Widjaja mengatakan bahwa Misi adalah Sebagai orang percaya, menyelesaikan amanat agung adalah tugas 
gereja Tuhan dalam hal ini adalah orang percaya, misi yang harus di jalankan ${ }^{10}$ dengan demikian penginjilan yang dilakukan menjadi tugas bersama untuk membawa orang untuk mengenal Kristus secara pribadi sesuai dengan amanat Agung.

\section{Dialog sebagai wujud menghadirkan kerajaan Allah}

Dialog merupakan salah satu wujud konkret partisipasi Gereja dalam membangun Kerajaan Allah. RM, art. 12 menjelaskan Kerajaan Allah sebagai wujud keselamatan yang sudah dipersiapkan oleh Allah dalam Perjanjian Lama, dilaksanakan oleh Kristus, dan di dalam Kristus, serta diberikan kepada semua orang oleh Gereja yang berkarya dan berdoa demi perwujudannya secara sempurna dan pasti. Kerajaan Allah bukanlah suatu kenyataan eksklusif bagi orang-orang tertentu saja tetapi diperuntukkan bagi semua umat manusia. Hal ini telah ditunjukkan oleh Kristus sendiri selama Ia berkarya di dunia. Dengan demikian, Kerajaan Allah harus menjadi wawasan misioner Gereja. Eksistensi Gereja pertama-tama untuk mengabdi Kerajaan Allah dan melayani manusia. Atas dasar inilah Gereja senantiasa memperjuangkan nilai-nilai kebenaran, keadilan, kasih, perdamaian, dan seterusnya (Gal 5:22-23). Dalam dialog, tema-tema Kerajaan Allah tentang kasih, keadilan, dan perdamaian telah membangkitkan pemikiran yang baru bahwa arti keselamatan tidak lagi disempitkan pada peranan Gereja dengan segala kebijakan pastoralnya, tetapi pada partisipasi seluruh umat manusia. Dari sejak mula, hati Bapa adalah hati yang missioner, mencari jiwa yang terhilang, sebagaimana Yesus berbicara tentang utus dan mengutus untuk mencari yang terhilang dalam Yohanes 20:21, "Seperti Bapa mengutus Aku, juga sekarang Aku mengutus kamu." Sebelum Yesus naik ke sorga, dalam Kisah Para Rasul 1:8, ditegaskan kepada orang yang meng- ikutiNya sampai di bukit Zaitun, "Kamu akan menerima kuasa, kalau Roh Kudus turun ke atas kamu, dan kamu akan menjadi saksi-Ku di Yerusalem dan di seluruh Yudea dan Samaria, dan sampai ke ujung bumi." Alhasil, gereja mula-mula yang lahir di hari Pentakosta merupakan 120 dari jumlah pengikut Yesus yang tersisa pascakebangkitan-Nya yang mampu menggetarkan Yerusalem. ${ }^{11}$ Menghadirkan kerajaan Allah dibumi adalah merupakan tujuan Allah serta peran manusia untuk mewujudkan amanat Agung Tuhan.

\footnotetext{
${ }^{10}$ Fransiskus Irwan Widjaja, Daniel Ginting, and Sabar Manahan Hutagalung, "Teologi Misi Sebagai Teologi Amanat Agung," THRONOS: Jurnal Teologi Kristen 1, no. 1 (2019): 17-24.

${ }^{11}$ Ibid.
} 


\section{KESIMPULAN}

Melakukan Amanat agung adalah tugas setiap orang percaya untuk memimpin mereka untuk mengenal Tuhan lebih baik dan mereka masuk dalam kerajaan Allah dimana Allah berada. Dalam perkembangannya zaman yang semakin maju dan agama semakin banyak ini merupakan sebuah tantangan untuk memberitakan injil secara langsung kepada orang lain. Dalam situasi dan kondisi manapun orang kristiani harus menyampaikan injil kepada orang lain. Penginjilan yang tidak melukai agama lain adalah dengan melakukan penginjilan melalui dialog beragama. Dialog yang dilakukan adalah dialog yang menceritakan tentang kasih dan keselamta yang dilakukan Yesus yang dapat dilihat melalui gereja, dialog dilakukan dengan tujuan untuk menjalankan misi amanat Agung, dialog dilakukan untuk menghadirkan kerajaan Allah dibumi ini.

\section{KEPUSTAKAAN}

Banawiratma, Johannes B. Konteks Berteologi Di Indonesia. Jakarta: BPK Gunung Mulia, 1988.

Putra, Angga Permana. "Pengertian Post Modernisme." Postmodernis.Blogspot.Com. Last modified 2012. https://postmodernis.blogspot.com/2012/01/pengertian-postmodernisme.html.

Senduk, H L. Penginjil Yang Sukses. Jakarta: Yayasan Bethel, 2008.

Tomatala, Yakob. Teologi Misi. Jakarta: Leadershio Foundation, 2003.

Tong, Caleb. Menuju Tahun 2000-Tantangan Gereja Di Indonesia: Sebuah Bunga Rampai Dalam Rangka Peringatan 25 Tahun Kependetaan Caleb Tong. Bandung: Pusat Literatur Euangelion, 1990.

Tong, Stephen. Teologi Penginjilan. Jakarta: Lembaga Reformed Injili Indonesis, 1988.

Widjaja, Fransiskus Irwan, and Noh Ibrahim Boiliu. Misi Dan Pluralitas Keyakinan Di Indonesia. Yogyakarta: Andi Offset, 2019.

Widjaja, Fransiskus Irwan, Daniel Ginting, and Sabar Manahan Hutagalung. "Teologi Misi Sebagai Teologi Amanat Agung." THRONOS: Jurnal Teologi Kristen 1, no. 1 (2019): 17-24. 